\title{
Improving energy efficiency of urban electric transport system using autonomous energy sources
}

\author{
Abramov E.Y. \\ Department of electrotechnological units \\ Novosibirsk state technical university \\ Novosibirsk, Russian Federation \\ e.abramov@corp.nstu.ru
}

Kapustin A.V.

Department of electrotechnological units

Novosibirsk state technical university

Novosibirsk, Russian Federation

kapusta_nsk@mail.ru

\author{
Ivanov V.V. \\ Department of electrotechnological units \\ Novosibirsk state technical university \\ Novosibirsk, Russian Federation \\ ivanov.etk@yandex.ru \\ Alekseeva I.K. \\ Department of electrotechnological units \\ Novosibirsk state technical university \\ Novosibirsk, Russian Federation \\ alekseeva1201@mail.ru
}

\begin{abstract}
This paper is devoted to the study of the energy characteristics of the traction power system of urban electric transport, the development of a methodology for evaluating currents distribution in traction networks and the development of progressive concepts of traction power supply systems. For the implementation of sustainable energy-efficient operation of the power supply system of urban electric transport, the problems of shared use of photovoltaic energy sources and energy storage devices are considered; the conceptual solution of traction supply system on the basis of used capacities, with their substitution by the rational share of autonomous power sources capacities, are offered. The use of a two-sided power supply scheme of the traction network was justified and the need to regulate of currents distribution was shown. The traction network area of Novosibirsk tram was chosen, on which experimental measurements were made with different operating conditions. An analytical method of calculation the average power losses for different feed schemes of the traction network was developed. On its basis, a computer calculation program was created and the dependences of the relative losses were obtained by varying the difference in feeder voltages. The calculation data results showed the significance of potential effects when converting traction network areas into parallel feeder operation provided that the current distribution in the feeder zone is symmetric.
\end{abstract}

Keywords-energy efficiency; electric transport; traction network; traction substation; energy storage device; photovoltaic; current distribution; analytical calculation method

\section{INTRODUCTION}

The urban electric transport is one of the most important and energy-consuming city agglomeration users. Therefore, the arrangement of conditions of sustainable electric transport system development with contemporary high technology solution adoption is necessary for providing economic growth and improving the quality of people's lives.

The basis of any transport system is the power supply infrastructure. Satisfying modern requirements for the power supply system of urban electric transport comes in two main directions. The first is to maximize an improvement of system elements. However, the second direction-development of progressive systems of traction power networks in general is much more important for techno-economic effect [1]

The analysis of ensuring energy efficiency and reliability of power supply systems of electrical transport showed that a necessary condition for the implementation of its main objectives is the development of a number of theoretical and experimental questions. That primarily involves the development of electric and economic calculations of power supply devices, as well as a study of circuits and devices of traction networks [2].

Traction substations (TSS) and network work in conditions that are significantly different to the stationary work conditions of electric power plants. These differences are determined primarily by loads features of traction networks that are formed by overlapping currents, consumed by the traction motors and electric needs of its own composition - the daily rhythms of transport activity cause the necessity to operate the quantity of transport units, which satisfies the need for the transportation of the greatest passenger traffic, which occurs in the peak hours of transportation, and to remove the part of transport units from movement in the hours of the passenger traffic reduction. The situation will be aggravated with opening new lines and increasing the intensity of operation of the available lines. As a consequence, the general deficiency of capacities will increase and the urban electric transport system operation will be unstable. At the same time, electric energy process losses in TSS converter units and traction network are $15-20 \%$ by consumption to perform useful work [3].

The existing system of urban electric transport has the significant potential to reduce the cost of energy and material resources. One of the most perspective directions is to increase the efficiency of the use of recuperative braking energy. The modern stage of power engineering development induces the dissemination of decentralized power supply based on the 
combination of various energy sources. This direction in terms of traction networks supposes the use of parallel contact network feeding. Thus, two types of energy appear in the electric traction system: external - from the energy systems, and internal - from electrical braking and additional energy sources of limited power. The overlay of these energies will lead to a change in currents modes and traction network voltages. The significance of a well-established methodology for electrical calculations is obvious.

Lately, a number of works on solving the problem of braking energy use and optimization of the currents distribution in traction networks have appeared [4-7]. Questions of currents distribution had previously been dealt with in a number of monographs and educational literature. A common disadvantage of these works is an investigation of the operation modes of only the one substation area. The purpose of this work is to study the parameters of power supply, the development of a general methodology for evaluating currents distribution at transport lines and the development of progressive concepts of traction power networks.

\section{PREREQUISITES FOR TRANSITION TO TWO-SIDED POWER SUPPLY SCHEME WITH ADJUSTABLE CURRENTS DISTRIBUTION}

The following power schemes and sections in the substation area of the double line are used: separate or parallel single power supply; separate and parallel double power supply; the node with section pillars and parallel connection posts.

Sections with double power supply have a number of advantages in comparison with the single power supply scheme: up to $20-25 \%$ of reduced power loss; sections power redundancy of catenary (increased supply reliability) is provided; reduced power of traction substations converter units; increased substation area and probability of effective regenerative breaking energy use when it passes through the catenary. Thus, it creates more favorable input modes voltage, conditions of automation are improved and operating costs due to the reduction of energy losses are reduced.

Electric traction systems feature with double power supply sections is to combine the catenary with the multiple power sources circuit. A number of problems appear when sections with double power supply are connected sequentially. The system becomes sensitive to power supply voltages, uncertainty of currents distribution in catenary appears. When different parallel power supplies voltages, the so-called cross current appears. That can significantly degrade the performance indicators of electricity due to the growth of energy losses, negative impact on the functioning of electric stock, complications in protection relays work, catenary overheating, accelerated insulation deprecation, etc. Depending on the parameters of the power section, the value of power losses from the cross current in the double power supply scheme will be different. With a high asymmetry of currents distribution, it may exceed the amount of total losses of single power supply schemes.

That is why, during conversion of traction network areas into two-sided feed and during building a new urban traction supply system by one of the most important engineering projects, it is possible to use voltage inequalities of contiguous TSS for forcing reallocation of load in the feeder zone through voltage regulation $[4,5]$.

\section{EXPERIMENTAL STUDY OF TRACTION NETWORK ENERGY CHARACTERISTICS}

A number of measurements were made at traction substations in Novosibirsk (TSS №29, 7, 13). For measurements on the AC side of TSS №29, the power quality recorder FLUKE 1760 was used. For measurements on the rectified voltage side, the recorders developed by the authors were used. They were developed on the basis of the microcontroller ATMega_1760, voltage sensors LEM LV-25P of the Hall effect, optocouplers with compensating feedback to the op-amp. Table I presents the results of estimating the deviations in the voltage characteristics on the $10 \mathrm{kV}$ side of TSS №29 from the admissible values in accordance with GOST 32144-2013.

TABLE I. EVALUATION OF ELECTRICITY QUALITY CHARACTERISTICS

\begin{tabular}{|c|c|c|c|}
\hline \multicolumn{2}{|c|}{$\begin{array}{l}\text { Electricity quality } \\
\text { characteristics }\end{array}$} & Valid Values & $\begin{array}{l}\text { Experimental } \\
\text { evaluation }\end{array}$ \\
\hline \multicolumn{2}{|l|}{ Frequency deviation } & $\begin{array}{l} \pm 0.2 \mathrm{~Hz} \text { for } \\
95 \% \text { time and } \\
\pm 0.4 \mathrm{~Hz} \text { for } \\
100 \% \text { time }\end{array}$ & $\begin{array}{c}+0.036 /-0.046 \\
\mathrm{~Hz} \text { for } 95 \% \\
\text { time and } \\
+0.047 /-0.069 \\
\text { for } 100 \% \text { time }\end{array}$ \\
\hline \multicolumn{2}{|c|}{$\begin{array}{l}\text { Slow voltage changes (positive and } \\
\text { negative deviations) }\end{array}$} & $\begin{array}{l}\text { Not more } \\
\text { than } 10 \% \text { of } \\
\text { the nominal } \\
\text { for } 100 \% \\
\text { time }\end{array}$ & $\begin{array}{l}\text { Positive up to } \\
4.73 \% \\
\text { Negative up to } \\
0.77 \%\end{array}$ \\
\hline \multirow{2}{*}{ Flicker dose } & Short-term & $\begin{array}{l}\text { Not more } \\
\text { than } 1.38\end{array}$ & Up to 10.15 \\
\hline & Long-term & $\begin{array}{l}\text { Not more } \\
\text { than } 1\end{array}$ & Up to 4.43 \\
\hline \multirow{2}{*}{$\begin{array}{l}\text { Harmonic } \\
\text { components of } \\
\text { voltage } \\
\text { (nonsinusoidality) }\end{array}$} & $\begin{array}{l}\text { Harmonics } \\
\text { factor }\end{array}$ & \multicolumn{2}{|c|}{ Within the limits of the norm } \\
\hline & $\begin{array}{l}\text { Total } \\
\text { Harmonic } \\
\text { Distortion }\end{array}$ & $\begin{array}{l}5 \% \text { for } 95 \% \\
\text { time and } 8 \% \\
\text { for } 100 \% \\
\text { time }\end{array}$ & $\begin{array}{c}\text { Up to } 1.95 \% \\
\text { for } 95 \% \text { time } \\
\text { and } 2.27 \% \text { for } \\
100 \% \text { time }\end{array}$ \\
\hline $\begin{array}{l}\text { Coefficients of } \\
\text { voltage asymmetry }\end{array}$ & $\begin{array}{l}\text { In reverse } \\
\text { sequence }\end{array}$ & $\begin{array}{l}2 \% \text { for } 95 \% \\
\text { time and } 4 \% \\
\text { for } 100 \% \\
\text { time }\end{array}$ & $\begin{array}{c}0.4 \% \text { for } 95 \% \\
\text { time and } 0.43 \% \\
\text { for } 100 \% \text { time }\end{array}$ \\
\hline
\end{tabular}

Fig. 1 shows: External characteristic, dependence of efficiency, dependence of the power factor for the first unit of TSS №29; functions of load current statistical distribution of substations. Fig. 2 shows the statistical distributions of the voltages of TSS №29, 7 and 13, the voltage differences on the buses of TSS №7 and 13 and in the points of connection to the contact network with a two-sided scheme. Fig. 3 shows the estimation of the coefficient of active energy losses for TSS №29. The calculation of indicators of load graphs for single-sided feed was performed, the results are summarized in Table II.

The considered electricity quality characteristics are within the limits of normally admissible values. The probability of going beyond these limits tends to zero. Thus, distortions in the electricity characteristics do not have a significant impact on the operation of the electric transport complex, and the 
application of measures to improve these indicators will not have a noticeable effect.
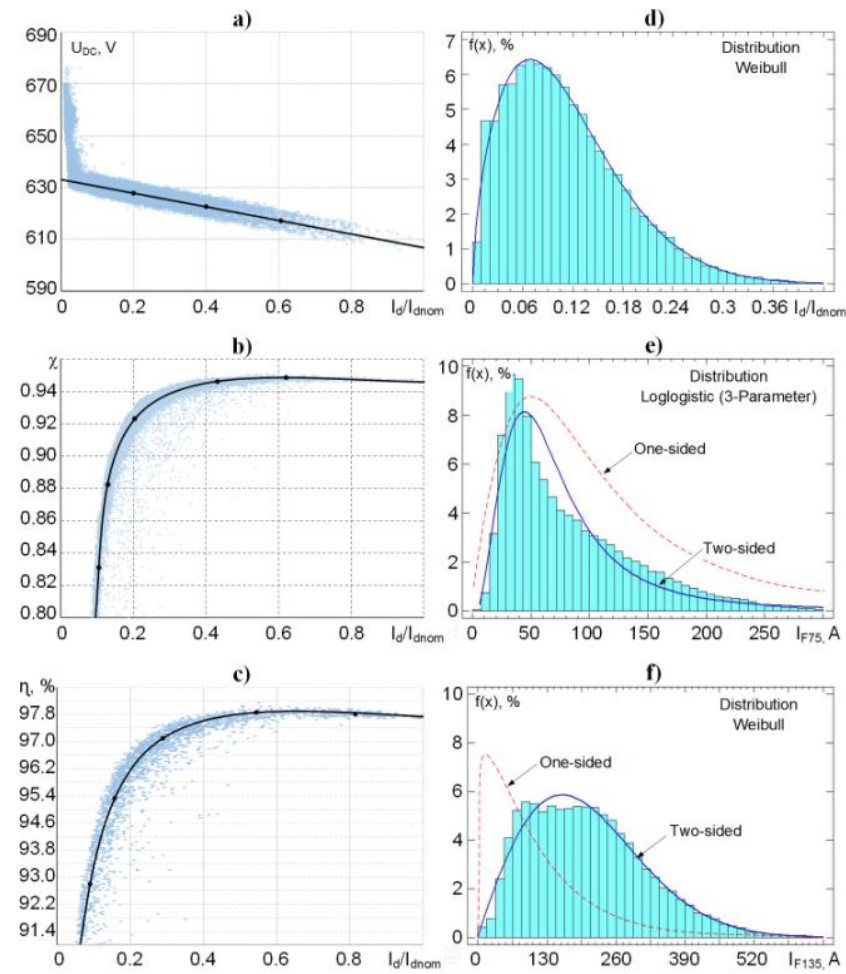

Fig. 1. External characteristic (a), dependence of power factor (b), dependence of efficiency (c) for the first unit of TSS №29; statistical function of probability density of the first unit TSS №29 current (d), feeder №75 current (e), feeder №135 current (f).
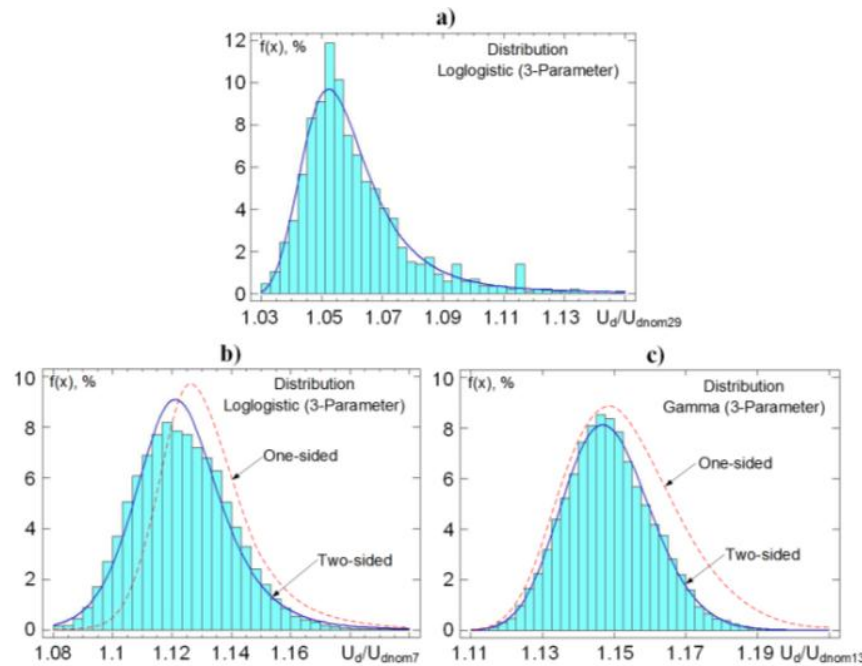

d)
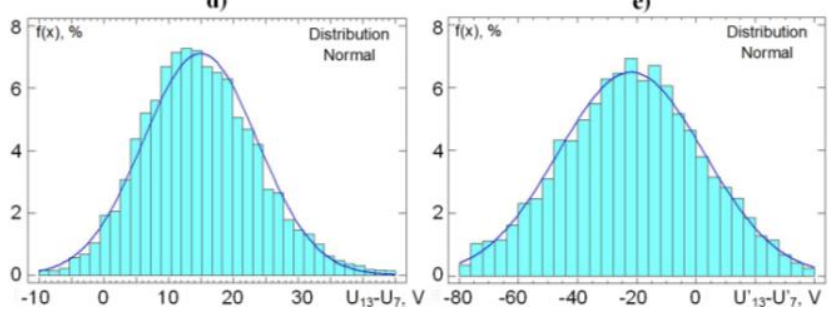

Fig. 2. The statistical distribution functions: a - voltage of TSS №29; b, cvoltages of TSS №7 and 13 with different supply schemes; d - voltage difference at buses of TSS №13 and 7; e - voltage difference at connection points to contact network.
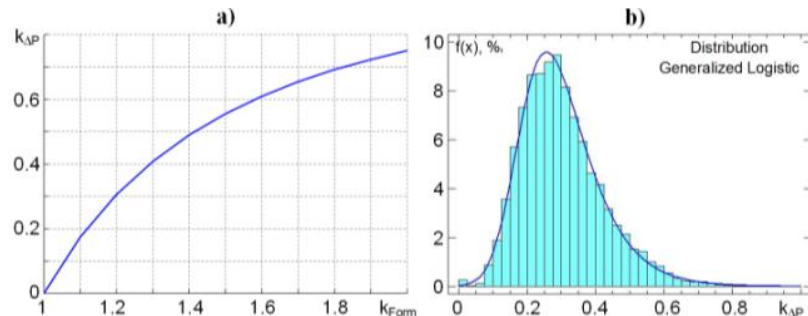

Fig. 3. Dependence of active power losses on unevenness of energy consumption (a); statistical estimation of the share of active losses from the unevenness of the load graph for the first unit of TSS №29 (b).

TABLE II. EVALUATION OF ENERGY CONSUMPTION INDICATORS

\begin{tabular}{|l|c|c|c|}
\hline Indicators & First unit TSS №29 & Feeder 135 & Feeder 75 \\
\hline $\boldsymbol{P}_{\text {avg }}, \boldsymbol{k W}$ & $61.2-84.8$ & $61.7-82.8$ & $58.6-155.8$ \\
\hline $\boldsymbol{P}_{\text {rms }}, \boldsymbol{k W}$ & $80.8-103.7$ & $95.3-122.4$ & $83.1-171.2$ \\
\hline $\boldsymbol{P}_{\max }, \boldsymbol{k W}$ & $369-485$ & $562-619$ & $403.2-617.8$ \\
\hline $\boldsymbol{T}_{\boldsymbol{P} \max }, \boldsymbol{h} / \boldsymbol{d a y}$ & $2.25-2.97$ & $1.94-2.42$ & $2.03-3.68$ \\
\hline$+\boldsymbol{V}_{\boldsymbol{P}}, \boldsymbol{k W} / \boldsymbol{s}$ & $545-709$ & $1043-1637$ & $571-2162$ \\
\hline $\boldsymbol{V}_{\boldsymbol{P}}, \boldsymbol{k W} / \boldsymbol{s}$ & $655-815$ & $1065-1892$ & $734-1776$ \\
\hline $\boldsymbol{k}_{\max }$ & $4.88-6.44$ & $7.3-9.1$ & $3.78-8.67$ \\
\hline $\boldsymbol{k}_{\text {form }}$ & $1.21-1.32$ & $1.46-1.54$ & $1.2-1.42$ \\
\hline $\boldsymbol{k}_{\text {in }}$ & $0.68-0.88$ & - & - \\
\hline $\boldsymbol{k}_{\text {load }}$ & $0.15-0.16$ & - & - \\
\hline $\boldsymbol{k}_{\text {use }}$ & $0.1-0.14$ & - & - \\
\hline
\end{tabular}

The most likely conditions for the operation of substations are when the voltage on their buses exceeds the permissible limit. Voltage measurements at TSS buses show the difference 
to $45 \mathrm{~V}$. A great impact of feeders resistance on voltage levels at connection points to contact network is evident.

Traction substations operate at low loads with respect to the installed power. In comparison with district substations of general purpose, the maximum coefficients are 4 times more unfavorable. The duration of the maximum load utilization is $13 \%$ of the daytime work time, the installed capacity is only used by $12 \%$.

Obviously, the energy performance is worse than the nominal values are, the most probable load currents meet the efficiency values of the order of $96 \%$ and the power factor of the order of 0.92 . In the nominal mode, their values will be shifted to $97 \%$ and 0.95 , respectively.

The obtained results indicate low technical and economic efficiency of the operation of the traction power supply system and determine a significant potential for improving the energy efficiency due to available possibility to reduce the active losses when aligning the load graphs.

\section{PROGRESSIVE CONCEPTS OF TRACTION POWER SUPPLY SYSTEMS}

The comprehensive analysis of the development opportunities of the urban transport system is necessary for the solution of the designated problem. In today's perspective representation, the key features of public trackless ground transport can be considered: reserve of autonomous move on the whole operating day; charge of on-board source at night at the lowest price of energy; partial isolation on the road from the other means of transport. For the tram system: powered by the wire system; realization of recuperative braking potential at the expense of energy source; high-speed movement; complete isolation from the other means of transport. For the individual electric vehicle: possibility of the rapid restoration of the charge level; developed infrastructure of charging stations.

In addition, to implementing the regenerative braking due to the exceptional possibilities of maneuvering by high power of supercapacitors, it is possible to significantly increase the use efficiency of the capacitor, by choosing the optimal operation algorithm, namely the parallel modes of the energy storage device and a power line. Using of energy storage devices for the train current limitation will allow one to use the braking energy and reduce losses in the traction power supply system, that is especially relevant in the conditions of the surface electric transport.

The most interesting are the alternative energy sources, especially photovoltaic technologies. In recent years the unprecedented growth of the target market of photovoltaic converters is observed in the world. The state support programs and the improvement of technologies provide the rapid decline in prices. However, new high-efficient technologies may change the picture dramatically, and for the Russian energy sector in particular [8].

It is necessary to take all these facts into account, because the development of this industry opens massive opportunities for the effective functioning of energy systems and specifies a path of future sustainable development of electric power industry - the rational use of traditional raw material resources with their gradual replacement by alternative.

The circuit with distributed connection of PV and energy storage systems will have the least energy losses proceeding from possible circuit with autonomous energy sources. Besides, such circuit will be more tailored to use PV systems with a large area.

The approaches to the integration of distributed TSS were built in 60 years, however these researches were not evolved due to engineering constraints. New prospects of inventing more effective power systems are emerging at this point and here the number of distributed power supply systems is growing every year $[9,10]$; in addition, a greater part of generation rating is accounted for solar energy.

Fig. 4 presents the feed circuit with parallel connection of contact wires in which the distributed connection of autonomous energy sources is used.

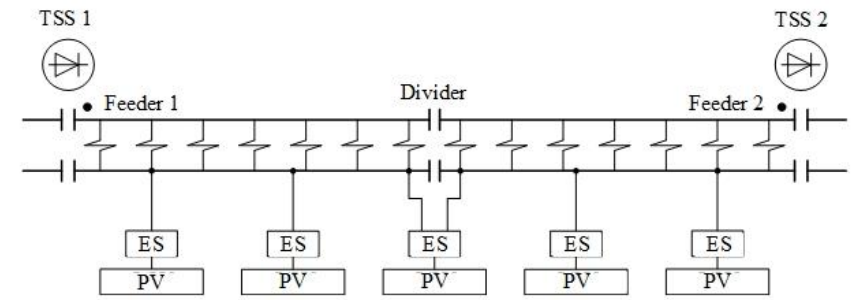

Fig. 4. Circuit of traction network with distributed energy sources.

The structure diagram solution is suggested for combining solar batteries with energy storage devices, it is shown in Fig. 5. The diagram concept is based on the integration of electricity storage and primary energy sources as single modules by using power and microprocessing electronic units.

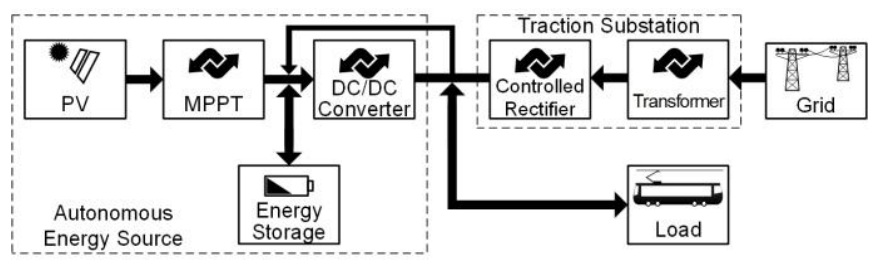

Fig. 5. Block diagram of the combined power supply system.

The basic operating mode is the daily traction load curve leveling on account of intelligent power flows distribution between TSS and autonomous energy sources. The distribution control is provided by means of autonomous energy sources DC/DC converter and controlled rectifier.

The load curve leveling principle. The energy storage device charge is carried out at night time hours at zero power consumption (its price is the lowest) as well as at PV power redundancy. The load factoring is provided on account of power generated by PV combined with storage power during the periods of low or zero energy consumption and during the periods of PV power redundancy. This PV energy use is more rational on peak busy hours rather than on its generation period. Fig. 6 shows the diagram of the system functioning. 


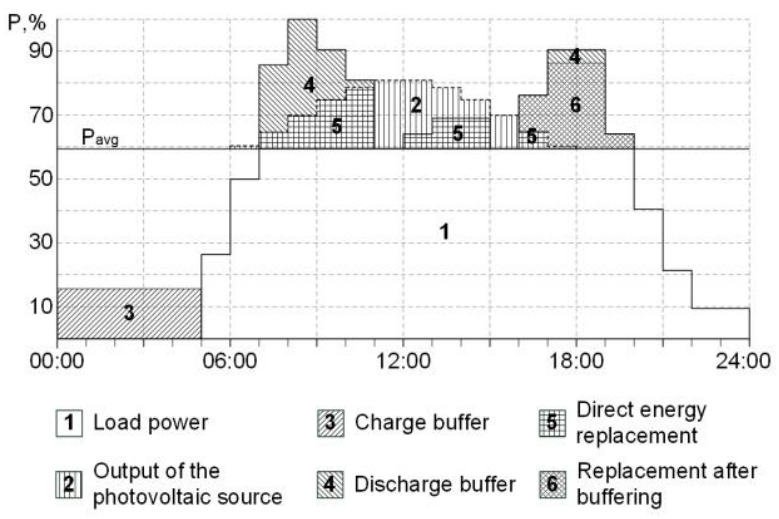

Fig. 6. The general principle of load peaks shaving.

In the general case, the operation is based on the principle of load peaks shaving - at the expense of the energy, generated by photovoltaic energy source in combination with buffered of energy in periods of low or absent energy consumption and in periods of excess generation of photovoltaic energy source.

The authors also proposed the concept of the integration of low-power energy storage devices and solar panels with a TSS. A generalized flowchart of the system operation algorithm is shown in fig. 7. The algorithm contains three active modes. The mode is determined depending on the current conditions in the traction network:

1. Charging the energy storage device from solar panels the energy storage device is charged by the excess power of the solar panels, if the traction load is insufficient;

2. Charging energy storage device from recuperating electric vehicle starts when the voltage in the contact network rises above the open circuit voltage, when an electric vehicle in the recuperation mode appears in the supply zone.

3. Discharging energy storage device on traction loads starts when an electric vehicle in the traction mode appears in the supply zone.

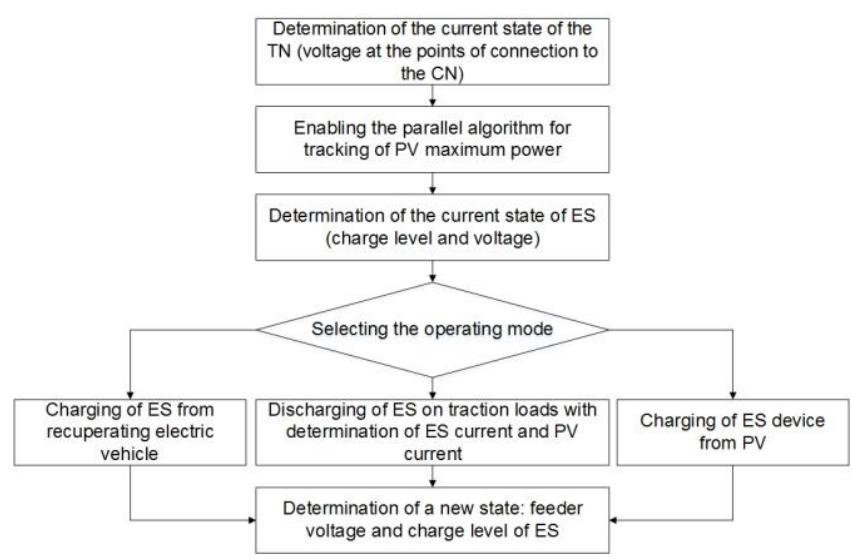

Fig. 7. Algorithm of adaptive current distribution control in a traction network.

In charge modes from an electric vehicle and a discharge on a traction load, the system monitors the voltage values at the connection points of the feeders and contact network and regulates the current to provide equipotential voltage mode. This ensures minimization of power losses.

\section{PERFECTION OF ANALYTICAL CALCULATION METHOD OF TRACTION NETWORKS}

TABLE III. EQUATIONS OF REFINED ANALYTICAL METHOD

\begin{tabular}{|c|c|}
\hline $\begin{array}{c}\text { Calculated } \\
\text { values }\end{array}$ & Equations \\
\hline \multicolumn{2}{|r|}{ Used scheme of one-sided feed } \\
\hline Feeders & $\Delta P_{F(1)}=I_{F(1) r m s}^{2} \cdot R_{F} ; I_{F(1) r m s}^{2}=I_{n}^{2} \cdot\left[n_{r m s}^{2}+n \cdot \beta\right]$ \\
\hline $\begin{array}{l}\text { Contact } \\
\text { network }\end{array}$ & $\Delta P_{C N(1)}=\frac{I_{n}^{2} \cdot L \cdot r}{3} \cdot\left[n_{r m s}^{2}+n \cdot \frac{3 \beta+1}{2}\right]$ \\
\hline \multicolumn{2}{|r|}{ Scheme of parallel connection of feeders } \\
\hline Feeders & $\begin{array}{c}\Delta P_{F(2)}=I_{A(2) r m s}^{2} \cdot R_{A}+I_{B(2) r m s}^{2} \cdot R_{B} ; \\
I_{A(B) r m s}^{2}=\frac{I_{n}^{2}}{L_{\Sigma}^{2}} \cdot\left[\frac{L^{2}}{4}\left(n_{r m s}^{2}+n \frac{4 \beta+1}{3}\right)+l_{B(A)}\left(L+l_{B(A)}\right) .\right. \\
\left.\cdot\left(n_{r m s}^{2}+n \beta\right)\right]+n_{r m s}^{2} \cdot \gamma_{4(5)} ; \\
\gamma_{1}=\frac{L}{L_{\Sigma}} \cdot\left(1+\frac{3 \cdot\left(l_{A}^{2}+l_{B}^{2}\right)}{L\left(L+2 \cdot\left(l_{A}+l_{B}\right)\right)}\right) ; \gamma_{2}=1+\frac{l_{A}+l_{B}}{L_{\Sigma}} ; \\
\gamma_{3}=\frac{L \cdot \Delta U}{L_{\Sigma}^{2}}\left(I_{n} \cdot\left(l_{A}+l_{B}\right)+\frac{\Delta U}{r}\right)\end{array}$ \\
\hline $\begin{array}{l}\text { Contact } \\
\text { network }\end{array}$ & $\begin{aligned} \Delta P_{C N(2)}= & \frac{I_{n}^{2} \cdot L \cdot r}{12} \cdot\left[n_{r m s}^{2}+n \cdot\left(2(\beta+1) \cdot \gamma_{1}-1\right)\right] \cdot \gamma_{2}+n \cdot \gamma_{3} ; \\
& \gamma_{4}=\left(\frac{\Delta U}{R_{\Sigma}}\right)^{2} \cdot\left(1+\frac{I_{n} \cdot r \cdot\left(L+2 l_{B}\right)}{\Delta U}\right) ; \\
& \gamma_{5}=\left(\frac{\Delta U}{R_{\Sigma}}\right)^{2} \cdot\left(1-\frac{I_{n} \cdot r \cdot\left(L+2 l_{A}\right)}{\Delta U}\right)\end{aligned}$ \\
\hline
\end{tabular}

Electric power supply devices calculations are one of the main means for the correct choice of appropriate system parameters. In addition, they serve for checking the conformity of selected parameters to all electrical requirements and conditions of the actual implementation of a specified amount of traffic.

For the calculation the analytical method of Professor Rosenfeld, based on the sizes of the movement, was used [11]. This method has been improved to take into account the difference in voltage and resistance of feeders. Jointly with the experimental voltage measurements on the feeders, this makes it possible to determine the limits of admissibility of the parallel feed operation mode and the requirements for the voltage regulation regimes. The equations are presented in Table III.

\section{CHECKING ANALYTICAL METHOD BASED ON EXPERIMENT}

For the considered section of the traction network, the dependences of the power losses on the voltage difference were obtained, which are presented in Fig. 8.

The figure shows the values of the relative losses corresponding to the experimental value of the mathematical expectation $\Delta U=14.9 \mathrm{~V}$. A comparison of these values with the results of calculations based on experimental data is presented in Table IV. The results of comparing the absolute values of the power losses obtained as a result of the 
experiment and the analytical calculation are presented in Table V.

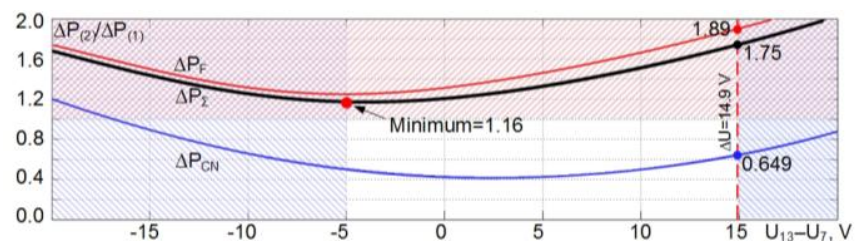

Fig. 8. Determination of the permissible range of application of two-sided supply.

TABLE IV. ESTIMATION OF RELATIVE DIFFERENCE BETWEEN RESULTS OF ANALYTICAL CALCULATION AND CALCULATION FROM EXPERIMENTAL DATA

\begin{tabular}{|l|c|c|c|}
\hline \multicolumn{1}{|c|}{ Parameter } & Experiment & $\begin{array}{c}\text { Analytical } \\
\text { calculation }\end{array}$ & $\boldsymbol{\delta}, \boldsymbol{\%}$ \\
\hline$\Delta \boldsymbol{P}_{\boldsymbol{F}(2)} / \Delta \boldsymbol{P}_{\boldsymbol{F ( 1 )}}$ & 0.62 & 0.649 & 4.68 \\
\hline$\Delta \boldsymbol{P}_{C_{N(2)}} / \Delta \boldsymbol{P}_{C N(1)}$ & 1.765 & 1.89 & 7.1 \\
\hline$\Delta \boldsymbol{P}_{\Sigma(2)} / \Delta \boldsymbol{P}_{\Sigma(1)}$ & 1.62 & 1.75 & 8.0 \\
\hline
\end{tabular}

TABLE V. COMPARATIVE EVALUATION OF EXPERIMENTAL RESULTS AND CALCULATED VALUES

\begin{tabular}{|c|c|}
\hline Indicators & First unit TSS №29 \\
\hline$\Delta \boldsymbol{P}_{C N(1) \_e x p} / \Delta \boldsymbol{P}_{C N(1) \_ \text {calc }}$ & 0.982 \\
\hline$\Delta \boldsymbol{P}_{F 75(I) \_ \text {exp }} / \Delta \boldsymbol{P}_{F 75(1) \_ \text {call }}$ & 1.026 \\
\hline$\Delta \boldsymbol{P}_{F 135(I) \_e x p} / \Delta \boldsymbol{P}_{F 135(I) \_c a l c}$ & 1.06 \\
\hline$\Delta \boldsymbol{P}_{C N(2) \_e x p} / \Delta \boldsymbol{P}_{C N(2) \_ \text {calc }}$ & 0.957 \\
\hline$\Delta \boldsymbol{P}_{F 75(2) \_\exp } / \Delta \boldsymbol{P}_{F 75(2) \_c a l c}$ & 1.096 \\
\hline$\Delta \boldsymbol{P}_{F 135(2) \_ \text {exp }} / \Delta \boldsymbol{P}_{F 135(2) \_ \text {calc }}$ & 1.062 \\
\hline
\end{tabular}

The difference between the results does not exceed $8 \%$. This is a good indicator, taking into account the measurement errors, the assumptions made and the approximate determination of the initial data for the calculation.

\section{DETERMINATION OF OPTIMUM VOLTAGE REGIME}

Based on the obtained analytical expressions, a calculation program was created in the Simulink environment (Fig. 9). This program allows one to determine the conditions for the effective use of two-sided supply scheme and the energy parameters of the currents distribution control modes in the traction network under any power supply scheme configurations.

In accordance with the timetable of tram routes operating on the investigated traction network area, traffic schedules in both directions were compiled. Based on these schedules, an average and effective amount of the electric vehicle was calculated for each feed zone. The mean current of the electric vehicle and its variation coefficient were determined on the basis of the data obtained by generalizing the experimental tests results under real operating conditions. At the same time, corrections were made for slopes, operating speed, length of distances and traffic conditions for the selected traction network area.

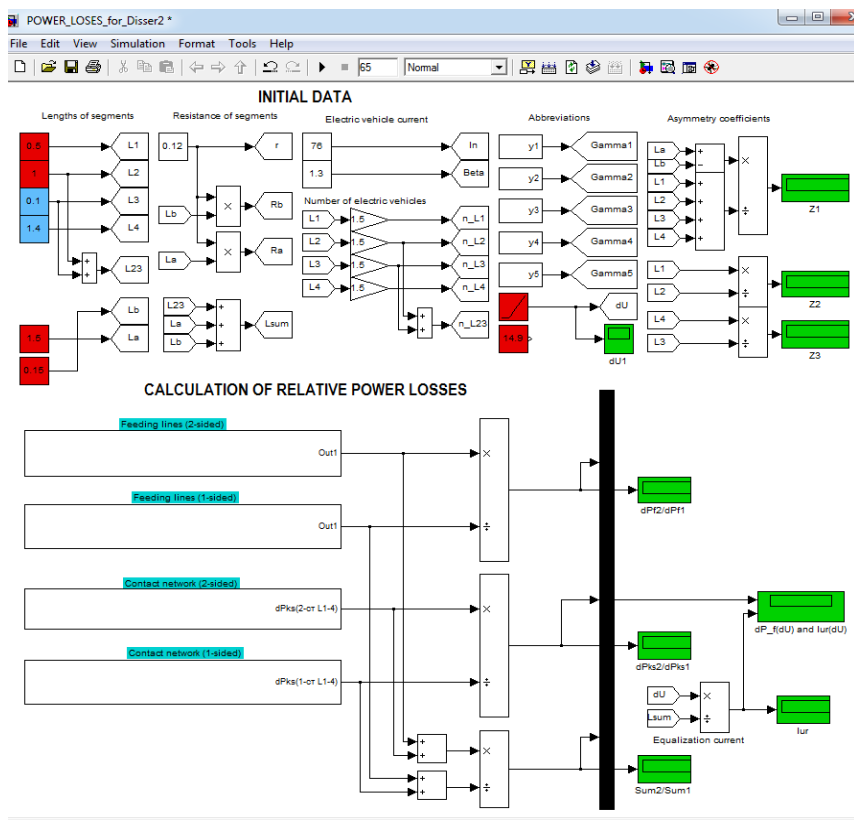

Fig. 9. Simulink-program for analytical calculation of traction networks.

The calculation of 64 variants of the circuit configuration was performed and the dependences of the relative power losses $\left(\Delta \mathrm{P}_{(2)} / \Delta \mathrm{P}_{(1)}\right)$ on the value of the additional voltage required to minimize losses in a given configuration of the circuit were obtained. This allowed us to determine the parameters of the circuits in which the two-sided mode would be most advantageous (fig. 10).

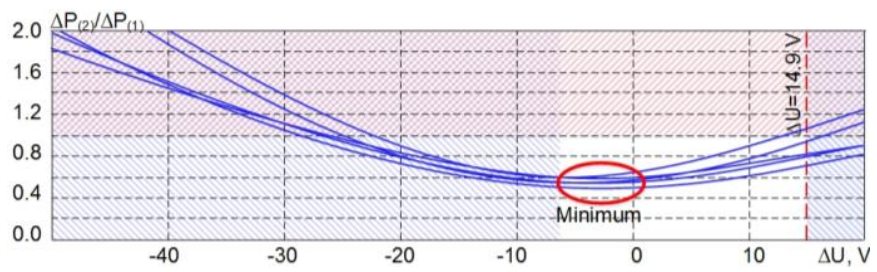

Fig. 10. Family of energy characteristics for most efficiency configurations of power supply scheme.

Fig. 10 shows the dependencies of the relative power losses on the value of the additional voltage for the best scheme configurations and the area of effective voltage regulation by means of autonomous energy sources. A minimum of total power losses will be achieved with a zero daily average voltage difference at the feeders connection points to the contact network, i.e. equipotential mode.

\section{CONCLUSION}

The paper presents the researchers' results on increasing the energy efficiency of power supply system for urban electric transport by means of PV and energy storage systems.

The expediency of applying a two-sided power scheme for traction network of urban electric transport was shown. It is shown that at conversion of traction network areas into twosided feed and at building a new urban traction supply system by one of the most important engineering projects is the use of 
voltage inequalities of contiguous TSS for forcing reallocation of load in feeder zone through voltage regulation.

A number of measurements were made at traction substations of tram in Novosibirsk. The obtained results indicate low technical and economic efficiency of the operation of traction power supply system and determine a significant potential for improving the energy efficiency due to available possibility to reduce the active losses when aligning the load graphs.

Two progressive conceptual approaches to the integration of traction networks with energy storage devices and solar batteries are proposed, the principles of their functioning are described.

The result of the development of easy for application of the traction network calculation analytical method was shown. It takes into account the difference of voltage and resistance of power supplies. This method in combination with experimental measurements of voltage at TSS buses allows one to determine permissible limits of parallel feed operation and requirements for regulation voltage mode.

A larger reduction in the total power losses can be obtained with a smaller difference of the feeders' resistance and / or a more symmetrical sectioning scheme of contact network. This indicates a benefit of decentralized traction power supply system whereby feeders have short length and this provides lower power losses in traction network.

A key feature of the urban traction system will be the most efficient use of available capacities of traction substations that is provided by the shift of consumption modes; automatic control of power equipment operation; the use of alternative energy sources to reduce the power load of the main system.

The offered integrated approach will allow one to solve tasks of rational use of energy resources with their partial substitution on alternative energy when the modernization of used sources and planning of new systems of power supply; will provide effective power supply of urban electric transport; will allow one to use the advantages of modern autonomous electric transport, will improve ecological safety of an urban environment, will provide wide opportunities for development of transport infrastructure and will significantly improve the performance of transportation process in general.

\section{Acknowledgment}

The reported study was funded by RFBR according to research project No. 16-08-00656.

\section{References}

[1] E. Y. Abramov, N. I. Schurov and M. V. Rozhkova, "Electric transport traction power supply system with distributed energy sources", IOP Conference Series: Materials Science and Engineering, Vol. 127, 7 p, 2016.

[2] E.Y. Abramov, A.A. Stang and S.A. Enkudinov, "Transformation of the urban electric transport system when using autonomous energy sources", Advanced Materials Research, Vol. 1040, pp. 778-783, 2014.

[3] V.I. Sopov, N.I. Schurov, Y.A. Prokushev and A.A. Shtang, "Increasing the efficiency of the use of electrical energy in the sub-subsystem of electric transport (Povishenie effektivnosti ispol'zovaniya elektricheskoy energii v subpodsisteme elektricheskogo transporta)", Improvement of technical means of electric transport (Sovershenstvovanie tehnicheskih sredstv elektricheskogo transporta), 2002, 189 p. [Digest of scientific works of the NSTU]

[4] B.A. Arzhannikov and A.A. Pyshkin, "Improving of DC power supply system based on automatic voltage regulation of traction substations (Sovershenstvovanie sistemi elektrosnabzheniya postoyannogo toka na osnove avtomaticheskogo regulirovaniya napryazheniya tyagovih podstanciy)", Ekaterinburg: "USURT Press", 2006, 116 p.

[5] V.I.Sopov, V.V. Biryukov, Y.A. Prokushev and Y.A. Rylov, "Analysis of power supply systems for rolling stock with various schemes of traction networks (Analiz sistem elektrosnabzheniya podvizhnogo sostava s razlichnimi shemami tyagovih setey)", Transport, Science, Engineering, Management (Transport, Nauka, Technika, Upravlenie) Vol. 2 (2008), pp. 49-53. [Digest of the VINITI RAS]

[6] V.V. Biryukov and A.V. Kulekina, "The calculation features of the electrical energy storage devices parameters in transport", The 11 International forum on strategic technology (IFOST 2016), pp. 41-43.

[7] N.I. Schurov, E.A. Spiridonov and A.V Larin, "Modes of traction power supply system in case of electric rolling stock equipped with energy storage", Applied Mechanics and Materials, Vol. 698, pp. 19-23, 2014.

[8] Photovoltaic (PV) research: National Renewable Energy Laboratory (NREL). Retrieved on http://www.nrel.gov/ncpv.

[9] N.W.A. Lidula and A.D. Rajapakse, "Microgrids research: a review of experimental microgrids and test systems", Renewable and Sustainable Energy Reviews, Vol. 15, pp. 186-202, 2011.

[10] B. Kroposki, R. Lasseter, T. Ise, S. Morozumi, S. Papathanassiou and N. Hatziargyriou, "A look at microgrid technologies and testing projects from around the world, making microgrids work", IEEE Power and Energy Magazine, Vol. 6, pp. 40-53, 2008.

[11] V.E. Rozenfeld, "Analytical calculation of electric railway networks (Analiticheskiy raschet setey elektricheskih zheleznih dorog)", The theoretical and scientific-practical peer-reviewed journal "Elektrichestvo", Vol. 9, pp. 6-17, 1947. 